\title{
EL FEDERALISMO BRASILEÑO
}

\author{
MARÍA ESTHER SEIJAS VILLADANGOS
}


SUMARIO

I. EVOLUCIÓN POLÍTICO CONSTITUCIONAL DE BRASIL EN CLAVE FEDERAL. 1. Unitarismo, colonialismo y monarquía 2. Federalismo embrionario: republicanismo y constitucionalismo 3. Consolidación del federalismo: redemocratización y cooperación. II. COMPONENTES DE LA FEDERACIÓN BRASILEÑA 1. La Unión 2. Estados federados 3.- Municipios 4. Distrito federal III. REPARTO COMPETENCIAL. 1. Desde un federalismo dual: competencias de la Unión y los Municipios. 2. Hasta un federalismo cooperativo: competencias privativas, comunes y concurrentes. 3. Las garantías del reparto competencial. IV. LA FINANCIACIÓN DEL SISTEMA FEDERAL. V. LAS RELACIONES INTERGUBERNAMENTALES: ENTRE LA COOPERACIÓN Y LA INTERVENCIÓN. VI. DILEMAS DEL FEDERALISMO EN EL CASO BRASILEÑO 


\title{
EL FEDERALISMO BRASILEÑO
}

\author{
MARÍA ESTHER SEIJAS VILLADANGOS, \\ Profesora Titular de Derecho Constitucional. Acreditada Catedrática de \\ Universidad. Universidad de León ${ }^{1}$
}

\section{EVOLUCIÓN POLÍTICO CONSTITUCIONAL DE BRASIL EN CLAVE FEDERAL ${ }^{2}$}

Dos ideas matriz han constituido el epicentro de la evolución constitucional de Brasil, democracia y federalismo. La magnitud física y poblacional de este Estado impone mayores exigencias a las fórmulas organizativas que han pugnado por implementarse en la, prácticamente, mitad del subcontinente de América del Sur. El tono rojo de las brasas a las que rememora el Palo Brasil, árbol con el que se asocia etimológicamente el nombre del Estado, acentúa lo candente de los debates y dilemas desde los que esbozaremos aspectos esenciales que caracterizan al federalismo en versión brasileña. Un federalismo centrípeto versus centrífugo, un federalismo dual versus cooperativo, un federalismo simétrico versus asimétrico o un federalismo nominal versus real o normativo, serán las dialécticas que marcarán la evolución constitucional de Brasil en clave federal.

\section{Unitarismo, colonialismo y monarquía}

La organización territorial de Brasil durante el período colonial, comienzos del siglo XVI, arranca desde un sistema de capitanías hereditarias, doce porciones irregulares del territorio colonial, donadas a particulares, comprometidos a explotarlas, poblarlas y defenderlas y sobre las que disfrutaban de unos poderes cuasi absolutos. Sobre esta planta semifeudal, Portugal, en 1549, implantaría un sistema de carácter

\footnotetext{
${ }^{1}$ Universidad de León. Facultad de Derecho. Área de Derecho Constitucional. Campus de Vegazana, s/n. 24007 LEÓN Email: meseiv@unileon.es

${ }^{2}$ Este primer apartado ha sido elaborado a partir de los trabajos de DA SILVA, José Alfonso, Curso de Direito Constitucional Positivo, Sao Paulo, Malheiros Editores, 2013, 36. ${ }^{a}$ edic., pp. 7-99; BERCOVICI, Gilberto, Dilemas do Estado Federal Brasileiro, Porto Alegre, Livraria Do Advogado Editora, 2004, pp. 9-54 y CONTIPELLI, Ernani, Sistema Federal Brasileño, Zaragoza, Fundación Manuel Giménez Abad, 2014, pp. 15-35.
} 
unitario con referente en la figura de los Gobernadores Generales, representantes nombrados por el Rey y que aglutinaban diversas funciones: militares, administrativas y judiciales. Este sistema unitario, inaugurado con Tomé de Sousa, quiebra con la creación de gobiernos regionales y la división de la colonia en dos Estados (1621), el Estado de Brasil y el Estado de Maranhăo, subdivididos en capitanías generales, que a su vez se estructuraban en capitanías secundarias. Cada una de ellas se dividiría en comarcas y en distritos. Esta proliferación de la municipalización se consolidará a lo largo de la evolución constitucional y culminará en su encumbramiento constitucional como elemento de la federación.

A comienzos del siglo XIX se abre una etapa monárquica con la llegada de Juan VI a Brasil, resultado de la presión napoleónica en Portugal. La Corte se instalaría en Río de Janeiro. La consideración de Brasil como Reino Unido a Portugal (1815), a modo pseudoconfederal, no impediría la proclamación de la independencia, el 7 de septiembre de 1822. El Estado brasileño independiente se singulariza por su forma de gobierno monárquica, frente a las opciones republicanas triunfantes en América del Norte y en las antiguas colonias españolas. El Estado Unitario imperial, con solo dos emperadores Pedro I y su hijo Pedro II, heredero a los 5 años y emperador a los 15, se asienta sobre la Constitución del Imperio de Brasil, de 15 de marzo de 1824. Territorialmente, este Estado se cimenta en las provincias, regidas por un presidente, nombrado por el emperador (art. 165), carentes de autonomía legislativa, y cuyos consejos generales (arts. 71-89) serían meros órganos deliberativos sobre los negocios más importantes de sus provincias. El eje político se polariza entre una monarquía centralizadora y el auge de unos poderes locales cada vez más activos, instigadores de diferentes rebeliones, inicialmente a favor de una monarquía federalista (proyecto constitucional de 1831), más derivando hacia un republicanismo que se asociaría a una mayor descentralización.

\section{Federalismo embrionario: republicanismo y constitucionalismo}

La dotación a las provincias de Asambleas Legislativas, en sustitución de Consejos Generales, en virtud de la Ley 16, de 12 de agosto de 1834 puede tildarse de la primera tentativa de descentralización real en Brasil, pese a su carácter efímero al ser suprimido su derecho a legislar solo seis años después. Un cambio en el planteamiento geoeconómico del Estado, desde el liderazgo norteño, referenciado en el azúcar, a la hegemonía de Sao Paulo, vinculada al café, se fusionó con el auge de un republicanismo, que asociado al federalismo, se consideraban como antídotos a la centralización y promotores de una redistribución de rentas que beneficiaría al sur. La proclamación de la República y la institución de un sistema federalista se produjo simultáneamente mediante el Decreto n. 1 de 15 de noviembre de 1889, que formaliza la instauración de los Estados Unidos de Brasil. Su constitucionalización se produce en 1891, Constitución de la República de los Estados Unidos de Brasil, de 24 de febrero, en la que se consigna la unión perpetua e indisoluble de las antiguas provincias, ahora Estados, y 
la creación de un distrito federal como capital de la Unión. Su inspiración se hallará en la Constitución norteamericana ${ }^{3}$ y, en menor medida, en las de la Confederación Helvética y de Argentina. Un federalismo dual, centrífugo, hegemónico, alejado de la realidad brasileña marcada por el protagonismo de los tres Estados económicamente más fuertes, Săo Paulo, Minas Gerais y Río Grande do Sul, y presidencialista sucumbiría ante el poder de los dueños de las tierras (coroneles) y ante alianzas, como la denominada «café con leche» que conllevaría la imposición de candidatos presidenciales desde esos Estados al resto del país. La Revolución de 1930 pone punto final a la primera República, abriendo un nuevo proceso constituyente que culminaría con la aprobación de la Constitución de la República de los Estados Unidos de Brasil, promulgada el 16 de julio de 1934. Mantiene los principios estructurales fundamentales (republicanismo, federación, presidencialismo), amplía los poderes de la Unión (arts..$^{\circ}$ y $6 .^{\circ}$ ) y enumera algunos poderes de los Estados a los que les asigna las competencias residuales (arts. 7 y 8. $^{\circ}$ ). Un federalismo cooperativo se divisa tímidamente, resultado del modelo alemán de Weimar seguido para su redacción. Pese a todo, Getulio Vargas revocaría dicha Constitución, otorgando la Carta Constitucional de 1937, en la que se potenciaría el papel del ejecutivo con una paralela limitación del legislativo (Estado Nuevo).

\section{Consolidación del federalismo: redemocratización y cooperación}

El restablecimiento de la democracia se consolidó con la Constitución de la República de los Estados Unidos de Brasil de 1946. Asienta la estructura de un federalismo cooperativo, enfatizando la reducción de los desequilibrios territoriales, desde organismos como la SUDENE (Superintendencia del Desarrollo del Nordeste). La capital se instala en Brasilia. Destaca, igualmente, el fortalecimiento y consolidación de la autonomía administrativa municipal (art. 28) con la consolidación competencial de la Unión (art. 5). La clave era el acercamiento entre los diferentes niveles de gobierno. Empero, tras una inestabilidad presidencial, un nuevo movimiento golpista culmina en la Constitución de 1967, quien reinterpretaría el federalismo cooperativo en aras de una potenciación de la Unión y del centralismo. Bajo el velo de un federalismo de integración, promotor del desarrollo y la seguridad nacional, se postulaba un federalismo meramente nominal que limitaría la autonomía de los Estados. Esa trayectoria se haría más evidente con la Enmienda Constitucional de 17 de octubre de 1969, en realidad una Constitución ex novo, en la que el gobierno de Juntas Militares (19691988) blindaría los poderes de la Unión.

Con la redemocratización de la década de los ochenta se abren nuevas perspectivas para el federalismo en Brasil. La vigente Constitución, promulgada el 5 de octubre de

3 WOLF, Paul, «Brasil en busca de una Constitución moderna: La Constitución de la República de los Estados Unidos de Brasil como Magna Carta a la moda americana», en Anuario Iberoamericano de Justicia Constitucional, n. ${ }^{\circ} 82004$, p. 380. 
1988, restaura la federación desde su artículo de apertura: «La República Federativa de Brasil, formada por la unión indisoluble de los Estados y Municipios y del Distrito Federal, se constituye en Estado Democrático de Derecho» (art. 1. ${ }^{\circ}$ ). El compromiso democrático de Brasil se enfatiza en el preámbulo del que llama la atención, más allá de las referencias a las pretensiones, legitimidad y origen del documento constitucional, el sujeto activo de la misma que se identifica con una sociedad fraterna, pluralista y sin prejuicios. El blindaje del carácter federal desde el vínculo de la indisolubilidad tiene por objeto dos finalidades básicas, «la unidad nacional y la necesidad descentralizadora» ${ }^{4}$. Una de las principales consecuencias es el veto a la secesión, que aún siendo implícito, el mero hecho de ser apuntada por un Estado legitima la intervención federal, como analizaremos (art. 34 CB). Su formulación vigente, un total de 250 artículos, se articula en nueve títulos (Título I, De los principios fundamentales, arts. 1-4; Titulo II, De los derechos y garantías fundamentales, arts. 5-17; Titulo III, De la organización del Estado, arts 18-43; Título IV, De la organización de los poderes, arts. 44-133; Título V, De la defensa del Estado y de las Instituciones Democráticas, arts. 136-144; Título VI, De la tributación y del presupuesto (arts 145169; Título VII, Del orden económico y financiero, arts. 170-192; Título VIII, Del orden social, arts. 193-232 y Título X, De las disposiciones constitucionales generales, arts. 233$250)^{5}$. Estos preceptos se complementan con el Acto de las Disposiciones Constitucionales Transitorias (arts. 1-97) un conjunto de normas temporales cuya finalidad es la transición armónica hacia el presente marco constitucional.

Desde el punto de vista territorial, la gran innovación de la Constitución brasileña del 88 fue la inclusión de los municipios como componentes de la Federación. Hasta este momento, las Constituciones previas habían potenciado su importancia, con autonomía gubernativa y funcional, pero habían otorgado a los Estados el poder para su creación y organización. El artículo 29 de la Constitución quiebra con estos antecedentes asignando a los municipios la potestad para autorregularse mediante ley orgánica, una auténtica "Constitución municipal» ${ }^{6}$, si bien se excluyen de la regulación de la concurrencia competencial (art. 24 CB) solo referida a la Unión, los Estados y al Distrito federal o de su participación en el Senado. Circunstancias que confirman la atipicidad del federalismo brasileño en este particular.

El modelo federativo brasileño se desgrana en los ocho capítulos del título III. Ahí se contemplan sus principios e instituciones, la descripción del régimen de distribución competencial, la regulación de sus unidades constitutivas (Unión, Estados Miembros, Distrito Federal y Municipios), la intervención de la Unión en los Estados,

4 DE MORAES, Alexandre, Constituição do Brasil interpretada e legislação constitucional, Sao Paulo, Editora Atlas, 2013, p. 59.

5 Algunas de dudosa inclusión en sede constitucional, como la atribución a la órbita federal del Colegio Pedro II, situado en Río de Janeiro (art. 242 §2).

6 BERCOVICI, Gilberto, Dilemas do Estado Federal Brasileiro, op. cit., p. 55. Esta catalogación de los municipios como entidades de la federación ha sido objeto de críticas severas por la doctrina. DA SILVA, José Alfonso, Curso de Direito Constitucional Positivo, op. cit. p. 103. 
así como la ordenación de la Administración pública, directa e indirecta, y sus agentes. La preocupación del legislador constituyente con respecto a la forma territorial federal queda latente por la minuciosidad de la regulación contenida en estos preceptos (arts. 18-43 CB). La consideración de la forma federativa del Estado como una cláusula de intangibilidad ante cualquier tentativa de reforma (art. $60 \$ 4 \mathrm{CB}$ ) respalda ese protagonismo federal en el constitucionalismo brasileño.

\section{COMPONENTES DE LA FEDERACIÓN BRASILEÑA}

La Constitución de la República proclama una estructura compleja que configura el modelo federal de Estado como resultado de la coexistencia de comunidades jurídicas responsables con órdenes normativos propios que se distribuyen según criterios de discriminación material de competencias fijadas en el texto constitucional. Estas instancias de poder son la Unión, los Estados miembros, el Distrito federal y los Municipios (Arts. 1 y 18 CB, STF. ADI 3293. 28-09-2007, p. 14). El nexo que une estas entidades federativas es la indisolubilidad (art. 1. ${ }^{\circ} \mathrm{CB}$ ).

\section{La Unión}

La Unión es un ente federativo, persona jurídica de Derecho público interno ${ }^{7}$, portadora de autonomía política con respecto a las demás unidades constitutivas de la federación y singularizada por implementar las competencias que dimanan del Estado Federal Brasileño.

Su regulación en sede constitucional (Título III, De la Organización del Estado, Cap. II De la Unión, arts. 20-24) se concreta en tres aspectos: la fundamentación de su existencia, merced a la identificación de los bienes de la Unión; la delimitación de su ámbito competencial (arts. 21, 22 y 23) y la estructuración de su organización mediante la regulación de los poderes constitucionales (Título IV, De la Organización de los poderes, arts. 44-135).

El afianzamiento de la existencia de la Unión, a través de la identificación de los «bienes de la Unión», se desarrolla relacionando las propiedades sobre las que se asienta (tierras, lagos, ríos, islas, mar territorial) y los recursos que de ellos se obtienen (recursos naturales, energía hidráulica o recursos minerales).

La existencia fáctica de la Unión se proyecta en una serie de atribuciones competenciales, desgranadas en los 25 apartados del art. 21 y los 29 del art. 22, sobre las que la Unión ostentaría una potestad exclusiva o privativa, con algunas matizaciones que señalaremos, y en otros títulos competenciales sobre los que la Unión desplegaría un régimen de competencias compartidas (art. 23) o concurrentes (art. 24).

7 TAVARES, André Ramos, Curso de Direito Constitucional, Sao Paulo, Editora Malheiros, 2008, p. 1009. 
La estructuración institucional de la Unión es la de los poderes constitucionales. El legislativo corresponde al Congreso Nacional, órgano bicameral compuesto por la Cámara de Diputados y el Senado Federal (art. 44 CB). El poder ejecutivo es ejercido por el Presidente de la República, auxiliado por el Vicepresidente y los Ministros de Estado (art. $76 \mathrm{CB}$ ). El poder judicial está compuesto por los Tribunales Regionales Federales y por la Justicia Federal (Supremo Tribunal Federal, Superior Tribunal de Justicia y los Tribunales Superiores sectoriales - trabajo, electoral y militar-) (art. $92 \mathrm{CB}$ ).

Desde una óptica federal, conviene enfatizar la institución del Senado como referente señero de la canalización de la participación de los Estados miembros en la formación de la voluntad política de la Federación. El Senado brasileño, por su composición más que por sus atribuciones, representa los intereses de los Estado miembros y del Distrito Federal, pero no de los Municipios que ven degradada así su consideración de entidades federativas. Sus principales atributos serían: paritario, asimétrico y formalmente territorial.

La paridad del Senado deriva, esencialmente, de su composición. A cada Estado miembro y al Distrito Federal le corresponde la elección de tres senadores, con dos suplentes. (art. $46 \S 3$ y Recurso Extraordinario 128.319, de 8 de marzo de 1991), en virtud de un principio mayoritario que considerará «electo al candidato que haya obtenido individualmente el mayor número de votos»(Recurso Extraordinario 115.492, de 2 de abril de 1993). Este sistema, inspirado en el modelo senatorial norteamericano, demuestra una igualdad de los poderes estatales que aspira a contrarrestar los desequilibrios de la Cámara de los Diputados, basada en la representación poblacional, además de conllevar una vocación homogeneizadora. El mandato tiene una duración de ocho años, produciéndose una renovación parcial de sus miembros cada cuatro años, en primer lugar referida a una tercera parte y, posteriormente, de las dos terceras partes restantes.

La caracterización del Senado brasileño como asimétrico deriva de la asignación al mismo, en sede constitucional, de una serie de funciones privativas (art. 52 CB) que le singularizan respecto a la Cámara de los Diputados con la que comparte funciones, en particular, relativas al proceso legislativo (arts. 48, 49 y $50 \mathrm{CB}$ ). Entre las funciones privativas del Senado, procede destacar su condición de órgano donde se sustancia el proceso de impeachment al presidente, vicepresidente, ministros o a los miembros de Supremo Tribunal Federal (art. 52 I y II CB); su protagonismo en la designación de cargos como magistrados, miembros del Tribunal de Cuentas o jefes de misiones diplomáticas de carácter permanente y su integración en el proceso de control de constitucionalidad de las leyes, al atribuirse al Senado la potestad para suspender, total o parcialmente, la ley declarada inconstitucional por el Supremo Tribunal federal. En esta relación de funciones privativas, la actuación del Senado respecto a las entidades federativas, en particular Estado miembros y Distrito Federal, se circunscribe al desempeño de tareas de control económico-financiero como la fijación de límites para operaciones de crédito y de deuda o el aval 
periódico de la funcionalidad del Sistema Tributario Nacional. Empero, en dicha relación de atribuciones no existe la identificación de funciones sustantivas respecto a los Estados y es por ello por lo que concluimos sobre ese carácter formalmente territorial del Senado ${ }^{8}$.

Finalmente, al hablar de la Unión, hemos de referirnos a los Territorios Federales que, careciendo de la consideración de entes federativos, son parte integrante de la estructura administrativa de la Unión (arts. 18. 2 y 33 CB). En la actualidad no existen Territorios Federales dado que las Disposiciones Transitorias que acompañaron a la vigente Constitución transformaron en Estados Miembros los Territorios de Roraima y Acre (art. 14 ADTC) y declararon extinto el Territorio Federal de Fernando de Noronha, ordenando su reincorporación al Estado de Pernambuco (art. 15 ADTC). Su eventual creación y las demás vicisitudes que les acompañen serán objeto de regulación en una ley complementaria.

\section{Estados federados}

Las antiguas 20 provincias que constituían el Imperio conforman actualmente los 26 Estados miembros de la presente federación brasileña: Acre, Amapá, Amazonas, Pará, Roraima, Rondônia, Tocantis (Región Norte); Alagoas, Bahía, Ceará, Maranhăo, Paraiba, Pernambuco, Piauí, Río Grande del Norte y Sergipe (Región Nordeste); Goiás, Mato Grosso y Mato Grosso del Sur (Región Centro Oeste, en él se ubica el Distrito federal); Espíritu Santo, Minas Gerais, Sao Paulo, Río de Janeiro (Región Sudeste) y la Región del Sur con Paraná, Río Grande do Sul y Santa Catarina.

La autonomía política de los Estados miembros se regula en la Constitución brasileña desde dos referentes: autonormación y autoorganización.

Partiendo del prius de su existencia, mediante la consignación de los bienes pertenecientes a los Estados (art. 26 CB) y de las normas relativas a su creación (art. 18 $\S 3 \mathrm{CB})^{9}$, el epicentro de la posición federal de los Estados se centra en su poder de autonormación, de primer grado, a través de la aprobación de la Constitución del Estado federado (art. 25 CB), implementación de un poder constituyente derivado que ha de observar los principios y que sería elaborada por cada Asamblea Legislativa Estatal en el plazo de un año desde la promulgación de la Constitución federal (arts. 25 CB y 11 ACDT). En un segundo nivel, la potestad de legislación estatal se vincula a una atribución competencial residual reflejada peculiarmente en la Consti-

8 «En Brasil, el bicameralismo no difiere del adoptado en países unitarios». BERCOVICI, Gilberto, Dilemas do Estado Federal Brasileiro, pp. 80-88.

9 A partir de la planta estatal inicial, de origen provincial, la formación de otros Estados será por división o desmembramiento. Cabe, por consiguiente, su transformación por incorporación entre sí. Es preciso la aprobación de la población directamente interesada, a través de plebiscito, y del Congreso Nacional por Ley Complementaria, oídas las respectivas Asambleas Legislativas estatales (arts. 18 § , 48. VI y $69 \mathrm{CB}$ ). No obstante, formalmente, el Congreso que regulará por mayoría absoluta no está vinculado por ninguna de esas decisiones previas. 
tución: «Están reservadas a los Estados las competencias que no les han sido prohibidas por esta Constitución» (art. 25 \& 1 CB).

La autonomía organizativa estatal se refiere, institucionalmente, a la creación de Asambleas Legislativas unicamerales (art. 27 CB), a la articulación de un poder ejecutivo residenciado en un Gobernador y un Vicegobernador, auxiliados por los Secretarios de Estado, y a un poder judicial, formado por la justicia estatal, cuya cúpula es el Tribunal de Justicia de cada Estado. Territorialmente, esta autonomía organizativa faculta a los Estados, mediante ley complementaria, a instituir Regiones, Aglomeraciones Urbanas y Micro-regiones, constituidas por la agrupación de municipios limítrofes con una finalidad funcional, para integrar la organización, el planeamiento o la ejecución de funciones públicas de interés común (art. 18 §3 CB).

\section{Los Municipios}

La tercera entidad integrante de la Federación brasileña son los Municipios. Pese a severas críticas doctrinales ${ }^{10}$, esta peculiaridad del federalismo brasileño que le convierte en una auténtica federación atípica, hace que los municipios ostenten una autonomía política de carácter normativo y organizativo.

La potestad de autonormación municipal se despliega a partir de la aprobación de la respectiva ley orgánica municipal, ex art. 29 CB, por el legislativo municipal -Cámara Municipal-, ley que siempre habrá de respetar los principios de la Constitución federal y de la Constitución estatal del Estado miembro en que se ubique. Esa doble legitimación priva la caracterización a esta ley como una modalidad de un poder constituyente derivado, remitiéndola a una vinculación a los poderes constituidos. En un segundo grado, la autonomía legislativa de los municipios les habilita, ex art. $20 \mathrm{CB}$, para legislar sobre asuntos de interés local, suplir las lagunas de la legislación federal y estatal y, entre otras materias, regular los tributos municipales; creación y organización de Distritos o la cooperación con la Unión y los Estados.

El autogobierno de los municipios se estructura en torno a un ejecutivo, con un Prefecto y un Vice-Prefecto, auxiliados por Secretarios Municipales (art. 29.I CB). En el ámbito legislativo, se dota a los municipios de un órgano designado como Cámara Municipal o Cámara de los Vereadores. Judicialmente, los municipios se integran en la organización judicial de los Estados. Dicha integración estatal de los municipios se evidencia, igualmente, en el dato de la creación, incorporación, fusión y desmembramiento de los municipios mediante ley estatal (art. $18 \S 4 \mathrm{CB})$, con los matices aportados por una enmienda constitucional aprobada en 1996.

10 DA SILVA, José Alfonso, Curso de Direito Constitucional Positivo, op. cit. p. 477. 


\section{Distrito federal}

El mimetismo respecto al federalismo norteamericano que caracteriza muchas federaciones, se evidencia meridianamente en el caso brasileño con la inclusión del Distrito Federal como un ente federativo, junto a la Unión, los Estados y los Municipios (art. $18 \mathrm{CB}$ ). Este se concibe como un espacio dotado de autonomía política diseñado para ubicar los órganos centrales del Estado federal en aras de una pretendida neutralidad respecto a los Estados miembros. Su autonomía normativa se concreta en una Ley Orgánica (art. 32 CB) aprobada por 2/3 de la Cámara Legislativa del Distrito. La prolongación de esta autonomía legislativa se vincula al desarrollo de competencias afines a las asignadas a los Estados y a los Municipios (art. 32 \$1 CB).

Orgánicamente, su autonomía provee la elección directa por los ciudadanos de un Gobernador de Distrito y de unos Diputados distritales que integrarán la Cámara legislativa. Esta naturaleza estatal afianza su singularidad con la utilización de los órganos del poder judicial o de servicios como Policía y Bomberos de titularidad de la Unión (arts. 21 XIII y XIV CB). Territorialmente, el Distrito Federal se divide en 31 regiones administrativas, estando prohibido su división en municipios (art. $32 \mathrm{CB}$ ).

En el territorio del Distrito Federal se encuentra Brasilia, la Capital Federal. Una ciudad inventada, fundada en 1960 y vinculada al diseño arquitectónico de Óscar Niemeyer. Brasilia, civitas civitatum, es una ciudad singular, en la que cohabita su condición de capital de la República Federativa de Brasil, sede de sus tres poderes y sede del gobierno del Distrito Federal (art. 6 de su Ley Orgánica).

\section{REPARTO COMPETENCIAL}

El reparto de competencias es el elemento clave en todo Estado federal, por consiguiente su análisis en el caso brasileño es sustancial. No obstante, como en la mayoría de federaciones, «son notorias las dificultades para saber qué materias deben ser otorgadas a la competencia de la Unión, cuáles a los Estados y cuáles a los Municipios» ${ }^{11}$.

Unas consideraciones generales del reparto competencial en la Constitución de 1988 deben ser formuladas antes de profundizar en su especificidad y concreta articulación.

Primera, la combinación en sede constitucional de competencias exclusivas y privativas con competencias comunes y concurrentes. Esta alternancia denota la evolución desde un federalismo dual hacia un federalismo cooperativo, pautas que se utilizarán como guía en este apartado. La efectividad de dicho reparto es sincrónica a la vigencia constitucional, con lo cual la Constitución ofrece el marco de referencia

${ }^{11}$ DA SILVA, José Alfonso, Curso de Direito Constitucional Positivo, op. cit. P. 479. 
de ese reparto, el parámetro de su vigencia que no queda deferida a otras normas ni a otros poderes.

Segunda, el menor peso competencial de los Estados debido a una dilatada regulación de las competencias de la Unión y a una detallada atribución competencial a los Municipios. Podríamos hablar de un federalismo centralizado y con una vocación homogeneizadora.

Tercera, la utilización del principio de los «intereses predominantes» como eje del reparto competencial. Así, cuando la materia en cuestión requiere un tratamiento homogéneo o uniforme en todo el Estado, correspondería asignar las competencias a la Unión. Por el contrario, cuando sea preciso una regulación heterogénea, con énfasis en las particularidades territoriales, lo procedente es atribuir la competencia al Estado miembro. En los supuestos en los que se busque una primacía de los intereses locales, dicha competencia debería ser asignada a los municipios ${ }^{12}$. Sin embargo, la realidad es mucho más compleja que esta sencilla categorización. Cabría cuestionar si los problemas de la Amazonía deberían afrontarse desde una competencia de la Unión, o desde una de los Estados que se extienden sobre su territorio como, por ejemplo, Amazonas o Pará o, bien, desde las atribuciones de ciudades como Manaos o Coari o de cualquiera de los municipios de cada uno de esos Estados.

Cuarta, respecto a la técnica de reparto competencial. Desde una concepción dualista, bajo la cual cabría diferenciar espacios propios de actuación, podríamos, simplificando la casuística sobre cómo las federaciones afrontan el reparto competencial, identificar tres formatos constitucionales de referencia: ora, la enumeración de los poderes de la Unión, correspondiendo a los Estados las competencias residuales. Ej. EE.UU.; ora, la enumeración de los poderes de los Estados, atribuyendo a la Unión las competencias residuales. Ej. Canadá; ora, un sistema mixto de lista exhaustiva de las respectivas competencias de la Unión y de los Estados, con atribución adicional de la cláusula residual a uno de ellos. Ej. Venezuela o India.

La evolución de este paradigma dual o estático a un modelo cooperativo, instado por el modelo alemán, amplía esa relación rígida con la inclusión de ámbitos competenciales comunes donde las potestades de las entidades federadas comparten esferas de actuación o, sencillamente, concurren. En este contexto aludimos a las competencias compartidas, situación que deriva de la asignación de diversas funciones o potestades (legislar, reglamentar o ejecutar) a diversas unidades territoriales, mientras que aplicamos el término de concurrencia para aludir a aquellas competencias donde diferentes unidades ostentan potestades o facultades de la misma naturaleza sobre un ámbito material específico. V. gr. ambos pueden legislar, si bien uno regula sobre aspectos generales o directrices y otro sobre elementos complementarios.

12 STF ADI 3112, 26 de octubre de 2007. La Unión puede legislar sobre materias de predominante interés general sin que ello suponga una invasión de las competencias residuales de los Estados. 
A partir de estos presupuestos, la Constitución brasileña adopta un sistema híbrido desde el que se opta por una sui géneris técnica de federalismo dual, a partir de un sistema de listas que podríamos identificar como binario, al señalar exhaustivamente las competencias de la Unión (arts. 21 y 22 CB) y definir las competencias municipales (art. $30 \mathrm{CB}$ ). Ese esquema se completa con la asignación a los Estados de las competencias resultantes de su condición de beneficiarios de la cláusula residual (art. $25 \$ 1 \mathrm{CB}$ ). Esta técnica se modula, derivando hacia un federalismo cooperativo ${ }^{13}$, desde los siguientes considerandos. Primero, la potestad de legislar "privativamente» de la Unión, en lugar de exclusivamente. Esta circunstancia se traduce en la posibilidad de que los Estados legislen sobre cuestiones específicas de dichas materias, previa autorización o delegación de la Unión, a través de una ley complementaria (art. 22 parágrafo último). Segundo, la creación de áreas comunes en las que se prevén actuaciones de la Unión, los Estados, el Distrito Federal y los Municipios (art. 23). Estaríamos ante competencias compartidas, acumulativas o paralelas que implicarían la posibilidad de legislar o practicar ciertos actos en pie de igualdad, sin que la actuación de una entidad venga a excluir el ejercicio de competencia por parte de la otra que intervendría agregativamente. Tercero, la delimitación de sectores de legislación concurrente entre la Unión, los Estados y el Distrito Federal (art. 24 CB). Esta concurrencia se concreta con la atribución a la Unión de la potestad de legislar con carácter general, a los Estados de legislar de modo complementario sobre esas normas generales, competencia que se expandirá en caso de laguna normativa general en lo concerniente a la atención a sus particularidades y en la fijación de un principio de primacía, conforme al cual una ley estatal contraria a la federal verá suspendida su eficacia (art. 24 § 1-4 CB). Finalmente, los Municipios tienen la potestad para legislar completando la legislación tanto federal como estatal (art. 30 II CB).

Quinta, la ejecución competencial. Lejos de un federalismo ejecutivo, el sistema brasileño vincula la ejecución y, por lo tanto, la actuación de las respectivas administraciones a cada entidad federativa ${ }^{14}$, Unión, Estados, Distrito Federal y Municipios. (arts. 37-39 CB). La excepción a este sistema inmediato de ejecución viene dada por la presión de una cooperación en el ámbito de los títulos competenciales comunes entre todas las entidades federativas para lograr «el equilibrio del desarrollo y del bienestar en el ámbito nacional» (artículo 23 parágrafo último, reformado en 2006). Igualmente, la deriva hacia la consolidación de un federalismo cooperativo se realiza con la articulación de «consorcios públicos» $\mathrm{y}$ «convenios de cooperación» (art. 241 CB, reformado en 1998).

13 Sobre la evolución de un federalismo dual al federalismo cooperativo desde el referente norteamericano, véase. ALBERTI ROVIRA, Enoch, Federalismo y cooperación en la República federal de Alemania, Madrid, CEC, 1986, pp. 346 y ss.

${ }^{14}$ CONTIPELLI, Ernani: Federación y Estado autonómico. Estudio de Derecho Constitucional comparado Brasil-España, Granada, Comares, 2012, p. 60. 


\section{Desde un federalismo dual: competencias de la Unión y los Municipios}

La consolidación de la Unión como elemento central de la Federación se realiza por la atribución a ésta de una serie de competencias exclusivas que se vinculan a ámbitos sensibles de la soberanía estatal y, por consiguiente, no susceptibles de ser objeto de delegación. Su regulación se despliega en los 25 apartados del art. 21 CB. Así, en materia de relaciones internacionales y defensa del Estado, compete a la Unión: mantener relaciones con los Estados extranjeros y participar en las organizaciones internacionales (I); declarar la guerra y acordar la paz (II); asegurar la defensa nacional (III); permitir que fuerzas extranjeras transiten por el territorio nacional o permanezcan en él temporalmente (IV); autorizar y fiscalizar la producción y el comercio de material bélico (VI). Estas competencias se ejercerán atendiendo a los principios consignados en el art. 4 CB que regirán en las relaciones internacionales (independencia nacional, prevalencia de los derechos humanos, autodeterminación de los pueblos...) que culminan en la búsqueda por parte de la República Federativa de Brasil de «la integración económica, política, social y cultural de los pueblos de América Latina con vistas a la formación de una comunidad latinoamericana de Naciones» (art. 4, parágrafo único). En materia de orden público y orden político: decretar el estado de sitio, el estado de defensa y la intervención federal $(\mathrm{V})$; organizar y mantener el poder judicial del Distrito Federal y los Territorios (XIII); policía del Distrito Federal (XIV) y otras policías (XXII); conceder amnistías (XVII) o la defensa frente a calamidades públicas (XVIII). En el ámbito del orden económico y social: emitir moneda (VII); administrar las reservas cambiarias del país y fiscalizar las operaciones de naturaleza financiera (VIII); elaborar y ejecutar planes nacionales y regionales de ordenación del territorio y de desarrollo económico y social (IX); mantener el servicio postal y el correo aéreo nacional (X); explotar directamente o mediante concesión los servicios de telecomunicaciones (XI) y radiodifusión, energía eléctrica, navegación aérea y transporte ferroviario y acuático internacional o interestatal (XII a-d y XXI); servicios de estadísticas, geografía, geología y cartografía $(\mathrm{XV})$; sistema nacional de gestión de recursos hidráulicos (XIX); desarrollo urbano (XX); energía nuclear (XXIII); inspección de trabajo (XXIV); minerales preciosos (XXV).

Las atribuciones competenciales a los Municipios (art. $30 \mathrm{CB}$ ) se ciñen a legislar, exclusivamente o con carácter complementario, sobre asuntos de interés local (I); suplementar la legislación federal y estatal en lo que proceda (II); regulación de tributos municipales (III); competencias urbanísticas (VIII) a las que se une la prolongación a escala municipal de competencias de la Unión o estatales en materias como organización territorial y creación de Distritos (IV), prestación de servicios públicos (V y VI) o la protección del patrimonio histórico y cultural local (IX).

Una cláusula residual sui generis habilita a los Estados a ostentar competencias, desde una delimitación negativa, a partir de la fijación de una reserva competencial estatal en todo aquello «que no les está prohibido por la Constitución» (art. 25§1). Así, un Estado no podrá ostentar competencias de titularidad de la Unión, salvo 
autorización expresa ex. art. 22 parágrafo único, o de los Municipios. Por otro lado, las competencias prohibidas, no solo a los Estados, sino a todos los entes federativos son: el establecimiento de cultos religiosos, subvencionarlos, obstaculizar su funcionamiento o mantener con ellos o sus representantes relaciones de dependencia o alianza; rehusar la fe a documentos públicos o crear diferencias entre los brasileños o preferencias entre sí (arts. 19 1-III CB). La delimitación positiva de las competencias estatales aparece escuetamente mencionada en los apartados 2 y 3 de dicho artículo 25. Respectivamente, la explotación directa o mediante concesión de los servicios de gas canalizado y la institución de regiones metropolitanas, aglomeraciones urbanas y microrregiones.

Finalmente, al Distrito Federal se le atribuyen las competencias legislativas reservadas a los Estados y a los Municipios (art. 32 1 CB), coherentemente con su naturaleza híbrida estatal-municipal. Eso se traduce en que ostenta las competencias residuales propias de los Estados (art. $25 \S 1$ ), las concurrentes entre Unión, Estados y Distrito Federal (art. 3024) y las exclusivas y suplementarias de los Municipios (art. 30 I y II).

\section{Hasta un federalismo cooperativo: competencias privativas, comunes y concurrentes}

La potestad de la Unión de legislar, privativamente (art. 22 CB), a través de la atribución de competencias comunes - junto a Estados, Distrito Federal y Municipios- (art. $23 \mathrm{CB}$ ) o en régimen de concurrencia con dichos entes federativos (art. 24) abre la puerta a un federalismo cooperativo con diferentes matices y sobre ámbitos materiales diversos.

La cualificación «privativamente» habilita, previa aprobación de la una ley complementaria, a que los Estados legislen cuestiones específicas vinculadas a los títulos competenciales relacionados en el art. 22 CB. Sería un supuesto de coordinación. Esa autorización, delegación, marcará los límites de la actuación estatal de modo que cualquier trasgresión de los mismos se equipararía a «legislar sin competencia, calificándose dicha usurpación legislativa como acto de transgresión constitucional» (STF, ADI 4391, 20-6-2011). Esta competencia estatal delegada se ilustra con la posibilidad de fijación de un «mínimo salarial», habilitado por una ley federal (3/2000), para los trabajadores que no lo tenían definido por ley federal, convención o acuerdo colectivo de trabajo, realizada en Estados como Río de Janeiro o Santa Catarina (TSF ADI 4364, 16-5-2011). Es importante remarcar que la inexistencia de dicha ley habilitadora de la delegación cierra las posibilidades de actuación estatal, algo que no ocurrirá cuando hablemos de concurrencia competencial. La relación de ámbitos materiales incluidos en este precepto es de gran amplitud incluyendo, desde una remisión genérica a la legislación en derecho civil, comercial, penal, procesal, electoral, agrario, marítimo, aeronáutico, espacial o laboral (I), hasta la prestación de servicios públicos como el postal $(\mathrm{V})$, la regulación de derecho como los vinculados a nacionalidad, ciudadanía, naturalización (XIII), poblaciones indígenas (XIV) o emi- 
gración e inmigración (XV). En lo relativo al orden económico, destacamos la legislación sobre sistema de ahorro, captación y garantía del mismo (XIX) o la Seguridad Social (XXIII).

Un paso más en el avance cooperativo se abraza con la identificación de competencias comunes a todas las entidades federativas (art. 23 CB). Estaríamos ante una cooperación obligatoria donde las unidades territoriales desempeñarían una actividad paritaria y no excluyente. Los ámbitos materiales señalados por la Constitución abarcan desde una genérica «defensa de la Constitución, de las leyes y de las instituciones democráticas o conservar el patrimonio público»(I), hasta medidas sociales, «cuidar de la salud y de la asistencias pública, la protección y garantías de las personas con discapacidad» (II), la protección del medio ambiente (VI) o la promoción de programas de construcción de vivienda y la mejora de condiciones de habitabilidad y saneamiento básico (IX). El objeto de esa cooperación se evidencia en el parágrafo último del precepto, «el equilibrio del desarrollo y del bienestar en el ámbito nacional», una conexión entre Estado social y federalismo. El principal escollo de este avance cooperativo es la mención a la no aprobación, hasta el momento, de las leyes complementarias que habrían de fijar las normas para esa cooperación derivada de las competencias comunes.

Finalmente, la cooperación se implementa, bajo las directrices de una coordinación estatal, mediante la fijación de un ámbito de legislación concurrente entre la Unión, los Estados y el Distrito Federal, pero sin incluir a los Municipios (art. 24 CB), en lo que el Supremo tribunal Federal ha descrito como «condominio legislativo» (STF ADI 2344, 2-8-2002). Los ámbitos materiales sobre los que se proyecta esta concurrencia se glosan en los 16 apartados del precepto: la legislación concurrente puede regular disciplinas jurídicas tales como el derecho financiero y tributario, el penitenciario y el urbanístico (I); la responsabilidad jurídica en materia de daños medioambientales, a los consumidores o a bienes y derechos de valor artístico, estético, histórico, turístico y paisajístico (VIII); aspectos económicos como la producción y el consumo $(\mathrm{V})$ o derechos sociales como la educación (IX) o la protección y defensa de la salud (XII).

Las pautas para su aplicación, a las que nos hemos referido en las consideraciones generales, se sintetizarían en la potestad de la Unión para regular las cuestiones generales y la capacidad estatal para su suplementación, derivan en una serie de limitaciones que podemos condensar en cuatro asertos: primero, la Unión no puede establecer normas generales de contenido ilimitado puesto que con ello invadiría las competencias estatales (RE 815.499-Agr 18-9-2004); segundo, los Estados miembros no deben sobrepasar los contenidos de una regulación suplementaria, so pena de incurrir en inconstitucionalidad por invadir competencia de la Unión al extrapolar dicha limitación (ADI 1886, 5-8-2014); tercero, la inactividad de la Unión legitima a los Estados miembros y al Distrito Federal a ejercer una competencia legislativa plena sobre una materia al efecto de atender las particularidades de su territorio (ADI 1926, 10-9-1999) y, cuarto, esa expansión del alcance normativo estatal es transitoria, dado 
que si la Unión procede a cubrir esa laguna recuperará su primacía produciendo la suspensión de la eficacia de la ley estatal por invasión competencial (ADI 3098, 24-11-2005 o ADI 2818, 1-8-20

\section{Las garantias del reparto competencial}

El complejo sistema de reparto competencial diseñado por el constituyente brasileño halla su máxima garantía en un sistema judicial identificado en el art. 92 CB y en cuya cúpula se encuentre el Supremo Tribunal Federal, «guardián de la Constitución por expresa delegación del poder constituyente» ${ }^{15}$.

Una presentación esencial de la estructura y características del poder judicial brasileño obliga a subrayar su carácter híbrido ${ }^{16}$, influenciado por el modelo anglosajón y el continental Así, por un lado, el control de constitucionalidad en el sistema brasileño puede implementarse de una forma indirecta, a través de un control difuso ${ }^{17}$, y un modo directo, a través del control concentrado ${ }^{18}$. El órgano protagonista de este control abstracto ${ }^{19}$ es el Supremo Tribunal Federal (art. 101 CB). Está integrado por once miembros, Ministros, nombrados por el Presidente de la República y elegidos por el Senado, por mayoría absoluta entre brasileños de nacimiento cuya edad sea entre 35 y 65 años, con notable saber jurídico y reputación incuestionable (art. 2 Regimento Interno do STF). Su mandato es vitalicio ${ }^{20}$.

Las competencias del Supremo Tribunal Federal se enumeran en el art. 102 CB, siendo divididas en originarias, en aquellos supuestos en que el juicio se desarrolla en primera y última instancia, como es el caso de la acción directa de inconstitucionalidad o los conflictos entre la Unión y los Estados o entre estos y recursales, cuando el

15 ADI 2010, 12-04-2002.

16 BARBOSA DE LIMA, Luiza Rosa, «Régimen jurídico del control de constitucionalidad en Brasil», en DÍAZ REVORIO, F.J., Reflexiones sobre la Justicia constitucional en Latinoamérica, Cuencia, Ediciones de la Universidad de Castilla-La Mancha, 2013, p. 135.

${ }^{17}$ El control difuso de constitucionalidad, vinculado a la defensa de intereses subjetivos, legitima a cualquier ciudadano a acudir un órgano competente del poder judicial para resolver sobre una situación concreta en la que se produzca la vulneración de algún derecho como consecuencia de la aplicación de una ley que considere inconstitucional. Si, vía recurso, es el Supremo Tribunal Federal quien declara la inconstitucionalidad de la ley, a partir de una situación concreta, ésta se remitirá al Senado Federal quien dictará una Resolución que determine la suspensión de la ejecución de dicha ley (art. 52 X CB). El control difuso o incidental de constitucionalidad se ha reforzado desde el año 2004 con la inclusión del art. 103 A CB referido al dictado de Súmulas Vinculantes por parte del Supremo Tribunal Federal que tendrán su origen en la existencia de una situación de inseguridad jurídica generada por la controversia sobre la validez, interpretación y eficacia de normas jurídicas. Estas decisiones serán vinculantes para los demás órganos del poder judicial y para el resto de poderes públicos de todas las entidades federativas.

18 VIVEIROS, Mauro, El control de constitucionalidad: el sistema brasileño como un modelo híbrido o dual, Madrid, Universidad Complutense, 2011, pp. 182 y ss.

19

${ }^{20}$ GONÇALVES FERREIRA FILHO, Manoel, «La justicia constitucional en Brasil» en Anuario Iberoamericano de Justicia Constitucional, 1997, n. 1, pp. 57-66. 
proceso se debe a un recurso ordinario o extraordinario con base en instancias inferiores. El papel del Supremo Tribunal Federal en la concreción del federalismo brasileño es de gran trascendencia ${ }^{21}$.

La Constitución brasileña de 1988 prevé como acciones típicas del control abstracto de constitucionalidad las siguientes: la acción directa de inconstitucionalidad (ADI), la acción declaratoria de constitucionalidad (ADC) $)^{22}$; las acciones directas de inconstitucionalidad por omisión (ADO) y las disquisiciones de incumplimiento de preceptos fundamentales (arts. $102 \S 1$ y $103 \S 2 \mathrm{CB}$ ).

Tomando como referencia la garantía del sistema de reparto competencial y de la propia estructura federal del Estado, la acción directa de inconstitucionalidad, es el principal recurso en dicha clarificación ${ }^{23}$. Se puede interponer son respecto a leyes o actos normativos de la Unión, de los Estados miembros o del Distrito Federal, cuando ejerza competencias estatales. Las decisiones recaídas en este proceso tienen eficacia erga omnes y vinculan a todos los poderes públicos de las entidades federativas. Los sujetos que ostentan una legitimación activa para impulsar ese control concentrado de constitucionalidad están referenciados en el art. 103 CB. Esa relación incluye al Presidente de la República, las Mesas del Senado y de la Cámara de Diputados, la Mesa de la Asamblea Legislativa del Distrito Federal, el Gobernador del Estado o del Distrito Federal, el Procurador General de la República, el Consejo Federal de la Orden de los abogados de Brasil, un partido político con representación en el Congreso Nacional o una confederación sindical o entidad de clase de ámbito nacional.

En lo concerniente a la competencia originaria del Supremo Tribunal Federal para juzgar las causas que tienen su origen en conflictos entre la Unión y los Estados miembros, Unión y Distrito Federal y entre las Unidades constitutivas entre sí, e incluso con respecto a las entidades que componen sus órganos de administración indirecta, excluyendo a los Municipios ${ }^{24}$, lo que el Tribunal identifica como conflic-

21 ROBERTO ANSELMO, José, O papel do Supremo Tribunal Federal na concretização do federliamso brasileiro, Sao Paulo, Pontificia Universidade Católica, 2006, Accesible en (http://www.dominiopublico. gov.br/download/teste/arqs/cp011630.pdf).

22 La acción declaratoria de constitucionalidad parte de la existencia de un cuestionamiento de la validez de una ley de cuya aplicación penden procedimientos abiertos, derivándose la necesidad de una interpretación uniforme de la misma.

${ }^{23}$ El recurso extraordinario (RE) configurado como instrumento de apelación desde instancias inferiores, en un ejercicio difuso de control jurisdiccional de constitucionalidad también constituye una referencia jurisprudencial interesante a los efectos de clarificar situaciones conflictivas que derivan del reparto competencial realizado en la Constitución. V. gr. Art. 22 XXVII, competencia privativa de la Unión en materia de licitación y contratación en todas las modalidades por todas las entidades federativas. (RE 423.560 Rel. Min. Joaquín Barbosa 19-6-2012). Dentro del control abstracto de constitucionalidad el protagonismo en lo concerniente a reparto competencial se vincula a las acciones directas de inconstitucionalidad (ADI), siendo referidas en menor medida en este contexto, las acciones declaratorias de Constitucionalidad (ADC). V. gr. Con respecto al art. 22. XXV, competencia privativa de la Unión sobre Registros Públicos. (ADC 5, Rel. Min Ricardo Lewandoski, 5-10-2007).

24 ACO 1295 Agr Segundo 2-12-2010. 
tos federativos ${ }^{25}$ (ACO 1.062, AgR. de 25-8-2014) hay una abundante jurisprudencia emitida, mayoritariamente, con forma de Agravio Regimental en la Acción Civil Originaria. Las causas de los litigios son, principalmente, reclamaciones patrimoniales (ACO 1551-AgR 20-3-2012); abuso de autoridad (ACO 1010, 23-8-2011); la prestación de servicios de calidad (Petición 4680, 12-4-2011); malversación de patrimonio público federal, con causa de un conflicto negativo de atribuciones para la investigación de irregularidades en la utilización de recursos públicos municipales, instado desde la Unión hacia un Estado (ACO 1463 AgR 1-2-2012) o incumplimiento de convenios entre Estados y la Unión, reclamando resarcimiento de gastos por ejecución de obras públicas (ACO 453, 15-2-2008).

Un inciso final en este apartado dedicado a las garantías del sistema federal ha de referirse a la habilitación a los Estados miembros, art. $125 \$ 2$ CB para promover una acción ante el Tribunal de Justicia estatal con causa en la vulneración de la Constitución del Estado, parámetro de enjuiciamiento, por parte de la legislación estatal y municipal $^{26}$.

\section{LA FINANCIACIÓN DEL SISTEMA FEDERAL}

El sostenimiento de un sistema de reparto de competencias se remite, básicamente, a la pareja dotación de mecanismos para su financiación. Con esa finalidad, el Título VI de la Constitución brasileña, De la tributación y los presupuestos, regula prolija y exhaustivamente la actividad financiera de la Federación, desde los tributos que pueden ser creados por la Unión, los Estados, el Distrito Federal y los Municipios (art. 145), el reparto de los ingresos tributarios (art. 157 CB) y todo lo concerniente a las finanzas públicas — deuda, fiscalización financiera de las Administraciones, operaciones crediticias- (art. 163 CB). Este marco normativo se complementa con leyes de desarrollo elaboradas por la Unión (Ley n. 4.320/64, relativa al derecho tributario y la Ley n. 5.172766, Código Tributario Nacional), preconstitucionales, pero que enfatizan la importancia para el ordenamiento brasileño de las leyes complementarias ${ }^{27}$.

${ }^{25}$ El STF distingue entre un conflicto entre entes federados y un conflicto federativo. Aquel se refiere al litigio promovido por los miembros de la federación, mientras que este último, partiendo de la necesaria participación de dichos miembros en el proceso, tiene como causa una conflictividad que puede generar en una potencial desestabilización del pacto federativo. ACO 1846-AgR, 19-3-2014.

26 Resulta llamativo que este tipo de procesos está protagonizado en muchas ocasiones por Gobernadores estatales que cuestionan las normas aprobadas por su propia Asamblea Legislativa. PIMENTA RIGA, Magno, A jurisprudência do Supremo Tribunal Federal em Açoes referentes ao Federalismo, accesible en (http://www.sbdp.org.br/arquivos/monografia/107_Magno\% 20 Pimenta\%20Riga.pdf ), p. 20.

${ }^{27}$ CONTIPELLI, Ernani: Federación y Estado autonómico. Estudio de Derecho Constitucional comparado Brasil-España, op. cit., p. 99. 
Utilizando como guía el nivel de la intensidad de disponibilidad sobre determinada competencia financiera, exclusividad versus monitorización, un esquema del sistema financiero de la federación brasileña pasa por los siguientes asertos.

En primer lugar, las diferentes entidades federativas ostentan una serie de potestades financieras en régimen de exclusividad. Así, la Unión, de conformidad con el art. $153 \mathrm{CB}$ es competente para instituir impuestos sobre importación de productos extranjeros, exportación de productos nacionales, rentas o ganancias de cualquier naturaleza, productos industrializados, operaciones de crédito, propiedad territorial rural y grandes fortunas. En caso de guerra, impuestos extraordinarios comprendidos o no en su competencia tributaria (art. 154 CB). Las contribuciones sociales destinadas a la financiación del sistema de Seguridad Social (art. 149 CB). Los Estados miembros podrán instituir impuestos sobre la transmisión de bienes mortis causa, circulación de mercancías, propiedad de vehículos automóviles (art. 155 CB) y un impuesto finalista para sostener a sus servidores públicos (art. 149 §1). Los Municipios están autorizados para crear impuestos sobre la propiedad predial y territorial urbana, transmisión intervivos de bienes inmuebles y la prestación de servicios de cualquier naturaleza a excepción de los regulados en el artículo 155 CB competencia de los Estados y del Distrito Federal. Este último asume, en régimen de exclusividad, las competencias propias de los Estados miembros (art. 155 CB) y de los municipios (arts. 147 y 156 CB).

La habilitación de un régimen competencial común, conforme al cual cualquier entidad federativa puede ejercer su competencia tributaria, siempre respetando los principios constitucionales, se circunscribe a lo prescrito en el artículo 145 CB. Así, impuestos con diferente hecho imponible a los ya gravados por otra entidad, tasas derivadas del ejercicio del poder de policía o por la utilización, efectiva o potencial, de servicios públicos, específicos y divisibles, prestados al contribuyente o puestos a su disposición y una contribución a la mejora mediante la realización de obras públicas.

La delimitación negativa del sistema de financiación federal en Brasil se consigue mediante la regulación de una serie de limitaciones constitucionales a la potestad tributaria y que se pueden sintetizar en unos principios básicos: legalidad, irretroactividad, igualdad y no discriminación, anterioridad, interdicción de la libertad de circulación. Entre ellos destaca la prohibición de crear tributos interestatales o intermunicipales, designados por el STF como «inmunidad recíproca» (ADI n. 939, 18-3-94).

Este sistema estático, basado en la exclusividad de la titularidad se dinamiza, fruto de la resignación ante la realidad y la necesidad de introducir mecanismos de coordinación en los que la Unión ejerce una función de monitorización o tutela de las restantes entidades federativas. Con este presupuesto, se habilita un sistema de transferencias intergubernamentales basado en la atribución de unos porcentajes de lo recaudado por la Unión hacia los Estados, el Distrito Federal y los Municipios ${ }^{28}$. Esa

28 Así, pertenece a los Estados y al Distrito Federal el producto de la recaudación de la Unión sobre rentas y ganancias de cualquier naturaleza que incida en la fuente sobre rendimientos pagados (art. 157. I CB); el 20\% de la recaudación de los impuestos que la Unión estableciese como consecuencia de la competencia residual regulada en el art. 154. I CB (art. 157. II CB); el $29 \%$ del producto de la 
intervención del poder central tiene como finalidad «ajustar los intereses generales de la nación a las acciones de las unidades constitutivas» ${ }^{29}$. Esa monitorización a la que hemos aludido, se prolonga hacia los Municipios, conforme a lo establecido esencialmente en el art. 158 CB. Por ejemplo, el $50 \%$ del producto del impuesto de la Unión sobre la propiedad territorial rural se derivará a los Municipios.

Además de estos criterios orgánicos, las transferencias intergubernamentales tienen un marcado carácter finalista y social, del que no debemos desvincular el federalismo cooperativo practicado en Brasil ${ }^{30}$, articulándose fondos específicos en materia de erradicación de la pobreza, de protección de la salud o en materia de educación.

Este sistema complejo encuentra su contrapunto en la exigencia de transparencia que vertebra el artículo $162 \mathrm{CB}$. La exigencia de la divulgación, antes del último día del mes siguiente al de la recaudación de la cantidad recaudada y de los recursos recibidos. La Ley de Responsabilidad Fiscal del año 2000 evidencia la inoperancia de este precepto, buscando dar una mayor efectividad al mismo.

\section{LAS RELACIONES INTERGUBERNAMENTALES: ENTRE LA COOPERACIÓN Y LA INTERVENCIÓN}

La descripción realizada del federalismo brasileño ha evidenciado una inclinación desde un sistema estático hacia una implementación más realista de la mano de la regulación de mecanismos de cooperación ${ }^{31}$. Entre ellos, la Constitución se refiere a la cooperación como prolongación necesaria de las competencias comunes reguladas en el art. 23 CB. El trato constitucional a la cooperación que aquí se hace es genérico y desde un punto de vista meramente formal. El parágrafo único de dicho art. 23 señala la necesidad de que en el marco de las competencias comunes entre entidades federativas, se proceda a la aprobación de leyes complementarias que determinarán y concretarán dicha cooperación. Una regulación más específica de los mecanismos de

recaudación de la intervención en el dominio económico previsto en el art. 177 que deberá ser destinado a la financiación de programas de infraestructura en medios de transporte.

${ }^{29}$ CONTIPELLI, Ennani, Asimetrías en el federalismo fiscal y solidaridad, Granada, Comares, 2015, p. 97.

${ }^{30}$ Una de las principales dificultades de la descentralización de las políticas públicas y del federalismo fiscal inaugurado por la Constitución de 1988 fue su conciliación con las políticas sociales. Así, REZENDE, Fernando, «El federalismo fiscal en Brasil», en HERNÁNDEZ CHÁVEZ, Alicia, Hacia un nuevo federalismo, Méjico, FCE, 1996, p. 225.

${ }^{31}$ Un estudio de las relaciones intergubernamentales en Brasil puede verse en ARRETCHE, Marta, «Intergovernmental Relations in Brazil: An Unequal Federation with simetrical Arrangements», in PORIRIER, Johanne, SAUNDERS, Chreyl, KINCAID, John (Ed.), Intergovernmental Relations in Federal Systems. Comparative Structures and Dynamics. Forum of Federations/Forum des fédérations, Internationsl Association of Centers for Federal Studies (IACFS), Oxford University Press Canada, Ontario, 2015, p. 108-134. 
cooperación entre la Unión, los Estados, el Distrito Federal y los Municipios se formula prácticamente al final de su articulado, con una referencia a los consorcios y los convenios de cooperación (art. $241 \mathrm{CB}$ ). El contexto en el que se vertebran esas relaciones es el de la ejecución y su ámbito de aplicabilidad de extiende a la totalidad de las entidades federativas, Unión, Estados federados, Distrito Federal y Municipios. Formalmente se reitera la exigencia de la aprobación de una ley para su articulación y, materialmente, se vincula su desarrollo a la gestión asociada de servicios públicos, bien como transferencia total o parcial de tareas, servicios, personas y bienes esenciales para la continuidad de los servicios transferidos. La matización entre las fórmulas, consorcio o convenio, derivaría de la naturaleza de los sujetos implicados. Mientras en el consorcio las partes signatarias serían entidades de una misma especie, Municipio con Municipio, Estado miembro con Estado Miembro, y de carácter público; los convenios de cooperación habilitan la posibilidad de aunar entidades de diferente naturales, como la Unión con los Estados, los Estados con los Municipios e, incluso, entre entidades públicas y privadas ${ }^{32}$.

En un terreno diametralmente opuesto, más allá de la solución de conflictos a la que nos hemos referido al analizar los mecanismos de garantía del reparto competencial, la Constitución brasileña contempla un mecanismo extremo de preservación, implementación de un federalismo designado como coactivo, que es la intervención.

La relevancia de la inserción de mecanismos coactivos en el federalismo fue destacada por Hans Kelsen y ha sido asumida en la mayoría de los órdenes constitucionales de los Estados descentralizados (Estados Unidos, Alemania, Méjico, Australia, Austria, Italia, Portugal o España ${ }^{33}$. Excepcionalidad, taxatividad, estabilidad y viabilidad son los prius que singularizan el contenido del Capítulo IV, De la Intervención, del Título III, de la Constitución brasileña. (Mandato de Seguridad STF 21. 041, 13-3-1992, p. 16). La intervención se concibe como una garantía jurídica del vínculo federativo, que deviene en la imposibilidad de invocar un derecho unilateral a la secesión, y cuya utilización se postula como excepcional, vinculándose al cumplimiento de unos supuestos habilitantes taxativamente enumerados en los artículos 34 y 35 de la Constitución. Así, la Unión está facultada para intervenir en los Estados para: «I) mantener la integridad nacional; II) repeler una invasión extranjera o de una unidad de la federación en otra; III) poner fin a una grave alteración del orden público; IV) garantizar el libre ejercicio de cualquiera de los poderes en las unidades de la Federación; V) reorganizar las finanzas de la unidad de la Federación que: a) suspendiese el pago de la deuda justificada durante más de dos años consecutivos, salvo si fuese por motivo de fuerza mayor; b) dejase de entregar a los municipios los ingresos tributarios fijados en esta constitución, dentro de los plazos establecidos en la ley;

${ }^{32}$ DA SILVA, José Alfonso, Curso de Direito Constitucional Positivo, op. cit., p. 485.

${ }^{33}$ Cfr. SEIJAS VILLADANGOS, María Esther, "Answers to Spanish centrifugal federalism: asymmetrical federalism versus coercive federalism», en Perspectives on Federalism, Vol. 6, Issue 2, 2014 , pp. 178-183. En particular el significado del federalism coactivo o coercitivo, un estudio comparado y sus consecuencias. 
VI) proveer la ejecución una ley federal, orden o decisión judicial; VII) asegurar la observancia de los siguientes principios constitucionales: a) forma republicana, sistema representativo y el régimen democrático; b) los derechos de la persona humana; c) autonomía municipal; d) rendición de cuentas de la administración pública, directa e indirecta; e) aplicación del mínimo exigido de los ingresos resultantes de los impuestos estatales, comprendidos y procedentes de transferencias, en el mantenimiento y desarrollo de la educación y de las acciones y servicios de sanidad (agregado en virtud de la reforma constitucional n. ${ }^{\circ} 29$ de 2000)». Esa intervención de primer grado se complementa con la regulación de otro procedimiento, intervención de segundo grado, desde los Estados hacia los Municipios o desde la Unión hacia los municipios localizados en el Territorio Federal ${ }^{34}$. En ambas, el procedimiento es similar. La fase de impulso se asigna bien, al poder legislativo o ejecutivo que ha sufrido el impedimento para actuar o al Tribunal Supremo Federal, cuando el poder judicial es el objetivo de la coacción, cuando se actúa frente al incumplimiento de los principios constitucionales o en los supuestos de no ejecución de la legislación federal. Este mismo tribunal, junto al Superior Tribunal de Justicia y al Tribunal Superior Electoral impulsarán el proceso intervencionista en los supuestos de desobediencia de una orden o decisión judicial. Finalmente, el propio Presidente de la República podrá decretar la intervención en los supuestos de protección de la unidad nacional, el orden público y las finanzas públicas ${ }^{35}$. La intervención se formaliza en un Decreto del Jefe del Ejecutivo, ora Presidente de la República, ora Gobernador del Estado miembro, en el que se reflejan las medidas a adoptar (v. gr. la avocación de competencias conferidas a los Estados o a los Municipios), su duración y el eventual nombramiento de un interventor para su implementación. Esta decisión será sometida a la apreciación del Congreso Nacional o de la Asamblea Legislativa del Estado, ordinario o extraordinario, en el plazo de 24 horas. El objetivo de garantizar la unidad federal es el fundamento de estos mecanismos interventores. El abuso en el recurso al mismo entraría en clara colisión con lo puntual de su concepción ${ }^{36}$, que paradójicamente «no

${ }^{34}$ Los motivos son: el impago de la deuda durante dos años consecutivos, salvo motivos de fuerza mayor; la no redición de cuentas; el incumplimiento de la asignación de ingresos tributarios, en los mínimos exigidos, a políticas sociales en materia de educación y sanidad o la inobservancia de los principios constitucionales y el incumplimiento de una ley o de una orden o decisión judicial (art. 35 $\mathrm{CB})$.

35 La relación de sujetos legitimados para impulsar la intervención debería ampliarse al Procurador General de la República, figura afín a un Fiscal General del Estado, en el ejercicio de una acción directa de inconstitucionalidad, en los supuestos de que una ley o un acto normativo de un Estado miembro o de un municipio los principios constitucionales señalados en el art. $34 \S 7$, o ante la negativa por parte de esas entidades a ejecutar una ley federal (art. 34 §VI). Aquí el Supremo Tribunal Federal, una vez estimada la procedencia de la intervención, deberá comunicar a la autoridad afectada y al Presidente de la República las medidas para el cumplimiento de los mandatos constitucionales.

36 Sobre un abuso de la intervención federal en Brasil, véase FERNÁNDEZ SEGADO, Francisco, «El federalismo en América Latina», en FERNÁNDEZ SEGADO, Francisco: Estudios de Derecho Constitucional lationamericano, Perú, Editorial Adrus, 2012, pp. 292-293. 
es una excepción al principio federativo, sino por el contrario una consecuencia necesaria de ese mismo principio» ${ }^{37}$.

\section{DILEMAS DEL FEDERALISMO EN EL CASO BRASILEÑO}

Los senderos del federalismo, parafraseando a La Pergola, han llevado al federalismo brasileño a buscar un difícil equilibrio entre una voluntad descentralizadora y una necesidad unificadora; entre una tendencia centralizadora, ahondada en períodos de déficit democrático, y una voluntad descentralizadora impulsada desde los territorios; entre una tendencia pro homogeneizadora y simétrica y una voluntad de integrar y de afrontar diferencias que se manifiesta mediante el reconocimiento de asimetrías, en el caso brasileño de carácter administrativo y económico — las regiones administrativas art. $43 \mathrm{CB}$ y fondos de financiación destinados al desarrollo de las regiones más pobres art. $159 \mathrm{I} \mathrm{CB}$ — $^{38}$; entre un federalismo dual y un federalismo cooperativo; entre una federación atípica y original, por ejemplo derivada de la inclusión de los Municipios como entidades federativas, y una federación mimética con otros modelos federales, esencialmente el norteamericano, lo que redundaría en un tipismo ejemplar.

De todas estas tensiones, que no contradicciones, aflora una dialéctica entre un movimiento centrífugo y una reacción centrípeta que hemos tratado de ilustrar desde los mismos orígenes del federalismo brasileño, reparando en el origen federal de Brasil desde la conversión de las provincias en Estados, y que ha buscado el equilibrio, a veces la supervivencia con una tendencia marcadamente centralizadora, con una clara hegemonía de la Unión y de determinados Estados.

Los retos que se plantean al federalismo brasileño se multiplican por la magnitud poblacional y territorial en que se desenvuelve, por las dificultades de aparejar un desarrollo federal con un desarrollo social y con el requisito, ya insoslayable, de afrontarlos de la mano de mecanismos transparentes que solo se fundamentan en una consolidación democrática y vinculados a la implementación de la Constitución vigente, sin necesidad de acudir desmesuradamente a su reforma ${ }^{39}$ o a su mutación sistemática.

${ }^{37}$ RIBEIRO BASTOS, Celso, Curso de Direito Constitucional, Sao Paulo, Ed. Saraiva, 1982, p. 106.

38 TORRECILlaS RAMOS, Dircêo, O federalismo Assimétrico, Sao Paulo, Edit. Plêiade, 1998, pp. 261-325.

39 PATIÑO CAMARENA, Javier, «Constitucionalismo y reforma constitucional en Brasil», en PATIÑO CAMARENA, Javier, Constitucionalismo y reforma constitucional, México, UNAM, 2014, pp. 151-165. 
Title:

Brazilian federalism

\title{
Summary
}

I. BRAZILIAN CONSTITUTIONAL POLITICAL EVOLUTION IN A FEDERAL FRAMEWORK. 1. Unitarianism, colonialism and monarchy 2. Embryonic federalism: republicanism and constitutionalism 3. Consolidation of federalism: redemocratization and cooperation. II. COMPONENTS OF THE BRAZILIAN FEDERATION 1. The Union 2.- Federated States 3. Municipalities 4. Federal District III. COMPETENCIAL REPRESENTATIVE 1. From a dual federalism: competences of the Union and the Municipalities. 2. Up to a cooperative federalism: exclusive, common and concurrent competences. 3. The guarantees of the division of powers. IV. THE FINANCE OF THE FEDERAL SYSTEM V. INTERGOVERNMENTAL RELATIONS: BETWEEN COOPERATION AND INTERVENTION. VI. DILEMMAS OF FEDERALISM IN THE BRAZILIAN CASE

\section{Resumen:}

Las vicisitudes del Palácio da Alvorada que han ubicado a Brasil en la primera línea de las inquietudes mundiales se enmarcan más allá del diseño moderno que Niemeyer le imprimió en los años 60 de la pasada centuria en un marco que sobre un patrón federal ha evolucionado tratando de unir forma de gobierno y forma territorial de Estado. En el presente trabajo se analizan las claves del federalismo brasileño haciendo un imprescindible repaso histórico de su configuración e incidiendo en los rasgos característicos de esta Federación. Sus elementos estructurales, el complejo diseño competencial que implementa funcionalmente toda Federación, la evolución metajurídica del modelo de la mano de las relaciones intergubernamentales y el aspecto financiero con el que se ha de acompañar todo proyecto federal. Dos ideas matriz han constituido el epicentro de la evolución constitucional de Brasil, democracia y federalismo. La magnitud física y poblacional de este Estado impone mayores exigencias a las fórmulas organizativas que han pugnado por aplicarse en la mitad del subcontinente de América del Sur. Para conocer Brasil, es preciso adentrarnos en su configuración como Estado Federal.

\begin{abstract}
:
The vicissitudes of the Palácio da Alvorada that have placed Brazil in the forefront of global concerns are framed beyond the modern design that Niemeyer built in the 60s of the last century in a framework that has evolved on a federal pattern trying to unite form of government and territorial form of State. In this paper we analyze the keys of Brazilian federalism making an essential historical review of its configuration and focusing on the characteristic features of this Federation. Its structural
\end{abstract}


elements, the complex competence design that functionally implements every Federation, the metajuridical evolution of the model hand in hand with intergovernmental relations and the financial aspect with which all federal projects must be accompanied. Two matrix ideas have constituted the epicenter of the constitutional evolution of Brazil, democracy and federalism. The physical and population magnitude of this State imposes greater demands on the organizational formulas that have struggled to be applied in the middle of the South American subcontinent. To know Brazil, it is necessary to know its configuration as a Federal State.

\section{Palabras clave:}

Federación. Cámara de Diputados. Senado. Tribunales Regionales Federales. Justicia Federal.

\section{Key words:}

Federation. Chamber of Deputies. Senate. Federal Regional Courts. Federal Justice. 